\title{
Husbandry and environmental conditions explain temporal variability of wild fish assemblages aggregated around a Mediterranean fish farm
}

\author{
Mateo Ballester-Moltó ${ }^{1}$, Pablo Sanchez-Jerez ${ }^{2}$, Benjamín García-García ${ }^{1}$, \\ Felipe Aguado-Giménez ${ }^{1, *}$
}

${ }^{1}$ Instituto Murciano de Investigación y Desarrollo Agrario y Alimentario, Estación de Acuicultura Marina, Puerto de San Pedro del Pinatar, 30740 Murcia, Spain

${ }^{2}$ Departamento de Ciencias del Mar y Biología Aplicada, Universidad de Alicante, PO Box 99, 03080 Alicante, Spain

\begin{abstract}
The aggregation of wild fish around fish farms is spatially and temporally variable in terms of species composition and structure. In general, temporal variability has been less well studied than the spatial aspect of these aggregations. We analyzed temporal variability at different scales following a hierarchical sampling design, with year, season and time of day as the main factors, with the levels of the latter factor corresponding with feeding intensity at the farm. Environmental and production variables were considered, such as water temperature, photoperiod, feed supplied, number of stocked fish and stocked biomass. Dominant fish species were analyzed separately to determine possible segregation processes. The most relevant sources of variation in abundance and assemblage structure were seasonal changes among years and hourly changes with different feeding intensities between seasons. Feed supplied was the production variable that best explained the temporal pattern with respect to abundance, and this variable, combined with hours of daylight, determined the assemblage structure. Liza ramada and Sarpa salpa dominated the assemblage in winter and were always aggregated around the farm. Boops boops, Oblada melanura and Sardinella aurita dominated the assemblage in spring, summer and autumn, showing a marked seasonal pattern. These 3 species, although present around the farm most of the year, displayed periods of distinct maximum abundance corresponding to their reproductive period. This study emphasizes the importance of determining the temporal patterns in abundance of dominant species in order to better understand the interaction between fish farming and wild fish assemblages, and to ascertain the contribution of wild fish to the recycling of aquaculturederived wastes.
\end{abstract}

KEY WORDS: Fish farming - Husbandry $\cdot$ Photoperiod $\cdot$ Supplied feed $\cdot$ Temporal variability · Wild fish assemblage

\section{INTRODUCTION}

In marine cage fish farming, some resources are shared between wild biota and the reared animals, generating interactions between components of the natural and farmed environments. As a consequence of the farming process, some residuals (mainly or-

${ }^{*}$ Corresponding author: felipe.aguado@carm.es ganic wastes in the form of faeces and uneaten feed) are incorporated into the surrounding environment, stimulating biological activity in the vicinity of farming areas. This organic matter input is postulated to be the main cause of the aggregation of wild fish (Tuya et al. 2006, Fernandez-Jover et al. 2008) around fish farms all over the world: in the Mediter- 
ranean Sea (Dempster et al. 2002, 2005, Valle et al. 2007, Fernandez-Jover et al. 2008, 2009), Red Sea (Özgül \& Angel 2013), Canary Islands (Boyra et al. 2004), Scotland (Carss 1990), Norway (Bjordal \& Skar 1992, Dempster et al. 2010), Australia (Dempster et al. 2004) and Indonesia (Sudirman et al. 2009). However, the effects of fish farm wastes on the distribution and physiology of wild fish remain unclear (Uglem et al. 2014). This aggregation phenomenon has been described as being analogous to the functioning of a large fish aggregating device (FAD) (Dempster et al. 2002). However, the cage-fish-farming 'aqua-ecosystem' involves greater complexity than typical FADs because of the dimensions and intricacy of the farming facilities.

In the Mediterranean, wild fish aggregations around fish farms exhibit spatial and temporal variations in their composition and structure (Dempster et al. 2002, 2005, Valle et al. 2007, Fernandez-Jover et al. 2008, Segvić Bubić et al. 2011, Bacher et al. 2012, 2015). Spatial variability has been studied at different locations, depths, and distances from the farms (Dempster et al. 2002, 2004, 2005, Fernandez-Jover et al. 2008, 2009). In general, the closer the natural habitats are to the cages, the more abundant and diverse the assemblages of wild fish usually are (Dempster et al. 2002). However, temporal variability has been less well studied. Several authors have demonstrated a strong seasonal effect (Valle et al. 2007, Segvić Bubić et al. 2011), or interannual variations (Fernandez-Jover et al. 2008). Shorter-term temporal scales of variation have also been addressed (Sudirman et al. 2009, Bacher et al. 2015). However, none of these studies have incorporated both long and short temporal scales or their interactions.

Temporal variability is a result of interactions among environmental and local factors. The magnitude and duration of changes in assemblage dynamics in response to environmental variability largely depends on the scale of time and/or space on which the environmental processes occur (Schneider 1994). Therefore, temporal patterns cannot be completely understood without considering their driving variables. Fish are poikilothermic animals, and water temperature, together with photoperiod, influences their distribution and activity (Norton 1999, Madurell et al. 2004). This could cause segregation of different species over time, which could also affect the whole assemblage structure. Dempster et al. (2002) suggested that the variability in wild fish assemblages aggregated around fish farms may be due to changes in oceanographic and environmental conditions, or interactions between fish species, as it occurs in FADs (Deudero 2001). The wild fish assemblages at fish farms are mainly driven by the composition of the surrounding natural communities (Dempster et al. 2005). However, Fernandez-Jover et al. (2008) suggested that wild fish assemblages around cage farms may also be strongly influenced by environmental variables such as depth, coastal geomorphology and distance to the shore. In addition, some husbandry features such as feed supplied, stock biomass or number of stocked fish can also act as drivers of temporal variability around fish farms, and to date their influence has not been addressed. Only the study of Bacher et al. (2015) has considered the influence of fish farm feeding activity on wild fish assemblages. Feeding activity in fish farms varies throughout the day, so its intensity could have an effect on the short term temporal variability scales of the wild fish. Understanding the temporal dynamics of the wild fish, the role of the different species and the correlation with environmental and/or production variables (such as these mentioned above) could help us to anticipate the potential ability of wild fish to contribute to waste recycling and the reduction of waste output, i.e. their capability to mitigate adverse effects derived from organic loading (Dempster et al. 2002).

Thus, our goals were to determine how some key driving environmental and husbandry variables influenced the temporal variability of the wild fish assemblage aggregated around a fish farm at different scales, and to examine the segregation of dominant fish species over time.

\section{MATERIALS AND METHODS}

\section{Study area}

This study was carried out in a single open-sea fish farm, located along the SW Mediterranean Spanish coast. The facilities were located within a lease of $500000 \mathrm{~m}^{2}$. A total of 24 floating cages were arranged in 2 groups of 12 cages attached on a grid and consisted of a combined production of 1:4 gilthead seabream Sparus aurata and seabass Dicentrarchus labrax. Fish were fed once a day with extruded feed between 8:00 and 16:00 h. The farm was located $750 \mathrm{~m}$ away from the shore on a wide bay at a depth of 34 to $46 \mathrm{~m}$. There were no other cage aquaculture facilities in proximity of the study area. In the vicinity of the farm there was a well-developed seagrass meadow, a mäerl bed and deep rocky reefs with coralligenous communities. 


\section{Sampling and experimental design}

The wild fish assemblage aggregated around the farm was studied by visual censuses following the methodology described by Dempster et al. (2002). Visual census is a rapid and non-destructive method that allows a high degree of replication (HarmelinVivien \& Harmelin 1975, Harmelin-Vivien \& Francour 1992). The visual counts also provide better abundance estimations than other techniques in environments where mobile fish are an important component (Harmelin-Vivien \& Francour 1992). Visual counts were conducted by 2 SCUBA divers. The lead diver recorded fish species and abundance following the methodology of Harmelin-Vivien et al. (1985). A second diver, swimming about $4 \mathrm{~m}$ behind the first, recorded small or highly mobile species that might have gone unnoticed by the lead diver. Information recorded by both divers was cross-checked after each visual count to avoid duplicating the data. Each sampling event consisted of 6 independent visual counts of 5 min duration (as replicates). Both divers swam randomly between the cages; the water volume per replicate was approx. $11250 \mathrm{~m}^{3}$ (from the surface to $15 \mathrm{~m}$ depth $\times 15 \mathrm{~m}$ wide $\times 50 \mathrm{~m}$ length).

Sampling was conducted seasonally for 2 consecutive years, and consisted of 4 random samples taken within each season and at 4 different times: 8:00, 11:00, 13:00 and 16:00 h. These times of the day coincided with different feeding intensity regimes at the fish farm: at 8:00 h just before feeding started (no cages feeding), at 11:00 $\mathrm{h}$ when the farm was fully operational (high feeding intensity: more than $30 \%$ of the cages feeding simultaneously), at 13:00 h just before the first working shift occurred (medium feeding intensity: 10 to $30 \%$ of the cages feeding simultaneously), and at 16:00 $\mathrm{h}$ when the second working shift begun (low feeding intensity: 0 to $10 \%$ of the cages feeding simultaneously). Therefore, our experimental design consisted of 4 factors: (1) year (Y) with 2 levels (2012 and 2013), random (no aspect makes us suspect that there might be some underlying hypothesis under this timescale) and orthogonal ${ }_{i}(2)$ season (S) with 4 levels (winter, spring, summer and autumn), fixed and orthogonal to $Y_{i}(3)$ day (D) with 4 levels, random and nested within the interaction between $\mathrm{Y}$ and $\mathrm{S}_{\text {; }}$ and (4) feeding intensity (F) with 4 levels (no feeding, high, medium and low feeding intensity), fixed and orthogonal to all other factors. We did not include a control location since our aim was not to determine whether wild fish assemblages around a fish farm differ from those away from a farm, which has been studied by several authors (Dempster et al. 2002, 2009, Valle et al. 2007, Özgül \& Angel 2013).

\section{Environmental and production variables}

We selected environmental and production variables that could influence the physiology, phenology and aggregating behaviour of wild fish around the farm facilities, and therefore could potentially be driving temporal variability. Water temperature (YSI Pro 20 oxy- and thermometer) was registered daily at $10 \mathrm{~m}$ depth at approximately 08:00 h. Photoperiod (as hours of daylight) was obtained from the Spanish Meteorology Agency (www.aemet.es). Feed supplied, number of stocked fish and stocked fish biomass data for the whole farm over the study period came from the stock management models belonging to the fish farming contributor company, and will remain undisclosed as per the owners' request.

\section{Statistical procedures}

Analyses of wild fish assemblage

In order to determine different sources of temporal variability, wild fish total abundance data and whole assemblage structure were analyzed by means of a 4 -factor model (described above) using permutational multivariate analysis of variance (PERMANOVA; Anderson 2001). PERMANOVA was based on the Euclidean distances of normalized data for the total abundance data analysis, and on the Bray-Curtis dissimilarities (Clarke \& Warwick 1994) of square root transformed data (Clarke 1993) for multivariate assemblage structure data. These analyses were tested using 4999 residuals under a reduced model. Components of variations were estimated according to Fletcher \& Underwood (2002) to determine the contribution of the different sources of temporal variability to the overall variability. For total abundance and assemblage structure data, pairwise PERMANOVA post hoc tests were performed. Non-parametric multidimensional scaling (nMDS) was applied to visualize the temporal pattern of abundance data. SIMPER analysis was used to estimate the contribution of fish species to the dissimilarities between sampling times. All multivariate analyses were carried out using PRIMER-E software (Clarke \& Gorley 2006) with the add-on package PERMANOVA+ (Anderson et al. 2008). 
We used generalized additive models (GAMs) to describe the temporal dynamics of dominant species using the statistics package 'MGCV' in R (Wood 2011). The GAM equations consider that the expected abundance is zero when it matches with the mean abundance of the whole study period. The residence times of the dominant species were then determined as the periods in which the GAM estimated values higher than zero, minus the mean. The temporal patterns of dominant fish were described with regards to their reproductive period.

Correlation between wild assemblage and environmental and/or production variables

Relationships between total abundance data and environmental and production variables were assessed using Pearson's partial correlation test. We used the BIOENV routine from PRIMER-E based on Spearman's rank correlation test (Clarke \& Ainsworth 1993, Clarke \& Warwick 1994) to determine what environmental or production variable or set of variables could help to explain the temporal pattern of the wild fish assemblage structure.

\section{RESULTS}

\section{Assemblage structure of wild fish aggregated around the fish farm}

In the 768 visual counts conducted at the fish farm, nearly 3 million fish belonging to 23 species from 14 families were identified. The most common families were Sparidae (6 species) and Carangidae (5 species). In the case of Carangidae, due to the difficulty in discriminating the species Trachurus mediterraneus and Caranx rhonchus during the visual censuses when they formed mixed groups, and considering that both species function in the same ecological role, both species were recorded as a single taxon, namely 'scads'. Each of the remaining families was represented by a single species. See Table S1 in the Supplement at www.int-res.com/articles/suppl/ q007p193_supp.pdf for the average abundance of each species during the different sampling events.

Only a few species were present during all seasons at the fish farm: Boops boops (at a very low abundance during winter), Sarpa salpa and Liza ramada. The regular presence of large specimens of Thunnus thynnus thynnus (estimated length from 60 to $220 \mathrm{~cm}$ ) was noteworthy throughout the study period. In gen- eral, the most abundant species during the whole study period were $B$. boops $(40.97 \%)$, Oblada melanura $(25.41 \%)$, Sardinella aurita $(22.78 \%)$ and scads $(6.77 \%)$, regardless of the time scale. Per season, the most abundant fish species were $L$. ramada in winter, $B$. boops in spring and summer, and $S$. aurita in autumn. The remaining fish species contributed very little to overall abundance regardless of season.

Considerable temporal variability in total wild fish abundance and assemblage structure was observed at different time scales (Table 1). For both variables, there was large variability due to the interactions $\mathrm{D}(\mathrm{Y} \times \mathrm{S})$ and $\mathrm{D}(\mathrm{Y} \times \mathrm{S}) \times \mathrm{F}(\mathrm{p}<0.001)$, i.e. wild fish abundance and the assemblage structure randomly and significantly varied between feeding intensities within sampling days (Table 1). The most relevant significant differences came from the interactions $\mathrm{S} \times$ F (PERMANOVA, $p<0.05$ for total abundance, Fig. 1; $\mathrm{p}<0.01$ for assemblage structure) and $\mathrm{Y} \times \mathrm{S}$ (PERMANOVA, p < 0.05 for total abundance, Fig. 2); $\mathrm{p}<0.001$ for assemblage structure).

Total abundance in summer and autumn was significantly higher (pairwise PERMANOVA, p < 0.05) in the earlier times of the day (08:00 and 11:00 h), just before feeding started and at maximum feeding intensity. After 11:00 h, as feeding intensity declined, total abundance tended to decrease (Fig. 1). In summer, assemblage structure also differed significantly between the early (08:00 h) and no-feeding periods, and late $(16: 00 \mathrm{~h})$ and low feeding intensity samplings (pairwise PERMANOVA, $\mathrm{p}<0.05$ ). SIMPER revealed that the differences were caused by the higher abundance of $S$. aurita, B. boops, O. melanura and (to a lesser extent) by scads and Trachinotus ova-

Table 1. PERMANOVA results for total abundance of wild fish and assemblage structure around the fish farm. Y: year; S: season; F: feeding intensity; D: day; ${ }^{*} p<0.05,{ }^{* *} p<0.01$, ${ }^{* * *} \mathrm{p}<0.001$; ns: non-significant

\begin{tabular}{|c|c|c|c|c|c|}
\hline \multirow[t]{2}{*}{$\begin{array}{l}\text { Sources of } \\
\text { variation }\end{array}$} & \multirow[t]{2}{*}{ df } & \multicolumn{2}{|c|}{$\begin{array}{c}\text { Total } \\
\text { abundance }\end{array}$} & \multicolumn{2}{|c|}{$\begin{array}{c}\text { Assemblage } \\
\text { structure }\end{array}$} \\
\hline & & MS & $\mathrm{p}$ & $\operatorname{MS}\left(\times 10^{-3}\right)$ & $\mathrm{p}$ \\
\hline $\mathrm{Y}$ & 1 & 13748 & ns & 48503 & $* * *$ \\
\hline S & 3 & 191940 & $*$ & 286000 & $* *$ \\
\hline $\mathrm{F}$ & 3 & 2115 & $* *$ & 2773 & ns \\
\hline $\mathrm{Y} \times \mathrm{S}$ & 3 & 18835 & $*$ & 52989 & $* * *$ \\
\hline $\mathrm{Y} \times \mathrm{F}$ & 3 & 55 & ns & 2257 & ns \\
\hline $\mathrm{S} \times \mathrm{F}$ & 9 & 1294 & $*$ & 3659 & ** \\
\hline $\mathrm{Y} \times \mathrm{S} \times \mathrm{F}$ & 9 & 5938 & ns & 1610 & ns \\
\hline $\mathrm{D}(\mathrm{Y} \times \mathrm{S})$ & 24 & 297 & $* * *$ & 10686 & *** \\
\hline $\mathrm{D}(\mathrm{Y} \times \mathrm{S}) \times \mathrm{F}$ & 72 & 593 & $* * *$ & 2340 & **** \\
\hline Residual & 640 & 212 & & 1011 & \\
\hline Total & 767 & & & & \\
\hline
\end{tabular}




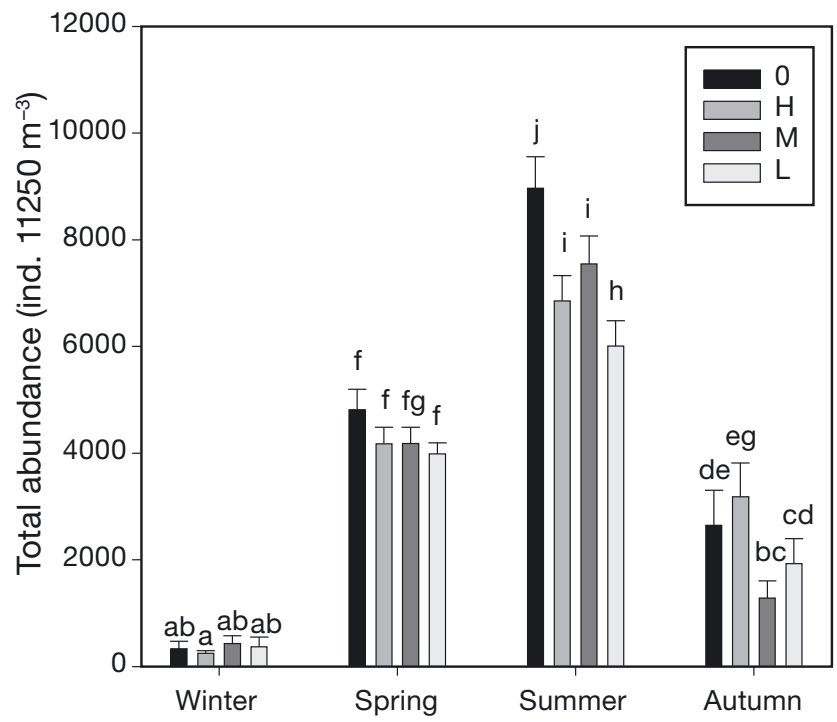

Fig. 1. Total abundance (mean $\pm \mathrm{SE}$ ) of wild fish (no. ind. $11250 \mathrm{~m}^{-3}$ ) aggregated around the studied fish farm at times of different feeding intensity within seasons. 0: non-feeding; $\mathrm{H}$ : high feeding intensity; $\mathrm{M}$ : medium feeding intensity; L: low feeding intensity. Different letters above bars indicate significant differences between the levels of the Season $\times$ Feeding

intensity interaction (pairwise PERMANOVA, $\mathrm{p}<0.05$ )

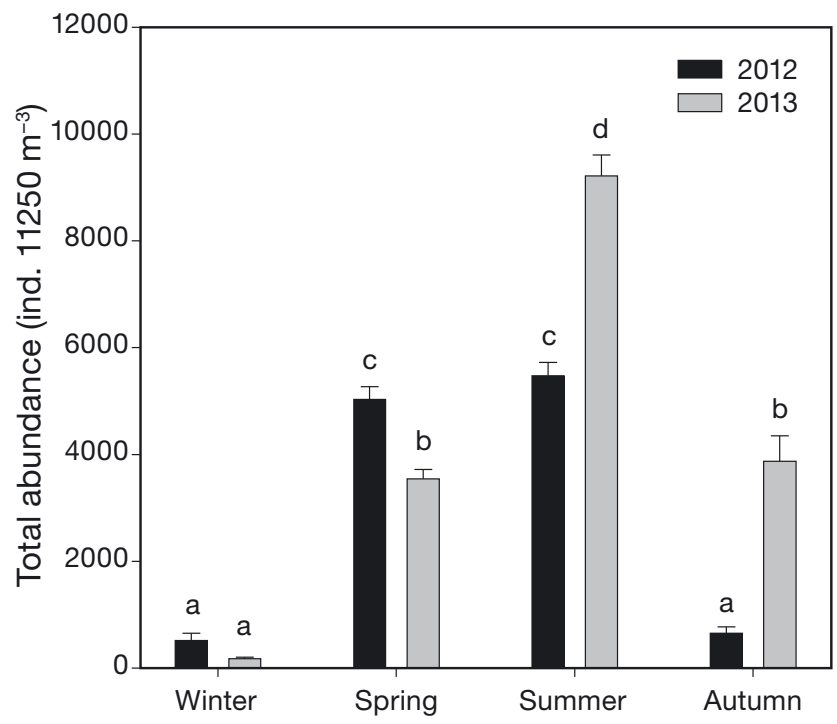

Fig. 2. Total abundance (mean $\pm \mathrm{SE}$ ) of wild fish (no. ind. $11250 \mathrm{~m}^{-3}$ ) aggregated around the studied fish farm during different seasons for 2 years. Different letters indicate significant differences between the levels of the Year $\times$ Season interaction (pairwise PERMANOVA; $\mathrm{p}<0.05$ )

tus before feeding started. In autumn samplings, wild fish assemblage structure differed between high $(11: 00 \mathrm{~h})$ and low $(16: 00 \mathrm{~h})$ feeding intensity periods (pairwise PERMANOVA, $\mathrm{p}<0.05$ ). SIMPER revealed that this difference was due to the varied behaviour of $S$. aurita, O. melanura and B. boops, which were the most abundant fish in this season, showing a nonsignificant increase in abundance from no-feeding time $(08: 00 \mathrm{~h})$ to high feeding intensity time $(11: 00 \mathrm{~h})$. After this time, as feeding intensity decreased the abundance of the dominant species declined notably. Conversely, L. ramada and $S$. salpa exhibited the lowest abundance when the dominant $S$. aurita, $O$. melanura and $B$. boops were more abundant. Likewise, when $S$. aurita, O. melanura and B. boops decreased in abundance, L. ramada and $S$. salpa increased from high $(11: 00 \mathrm{~h})$ to low $(16: 00 \mathrm{~h})$ feeding intensity times. For the remaining seasons, no significant differences were observed between feeding intensity periods at different times of the day.

Regarding the interaction of $\mathrm{Y} \times \mathrm{S}$, total wild fish abundance for 2012 was significantly lower in winter and autumn than during spring and summer (pairwise PERMANOVA, p < 0.001; Fig. 2). In 2013, total abundance was significantly lower in winter, higher in spring and autumn and peaked in summer (pairwise PERMANOVA, $\mathrm{p}<0.01$ ). In autumn 2013, total abundance variability was very high among days, and pairwise PERMANOVA ( $p>0.05$ ) was unable to discriminate this season from the others. The nMDS plot (Fig. 3) shows an evident subset of samplings (on the left side of the plot) formed by summer and spring assemblages from both years, and autumn 2013. However, pairwise PERMANOVA demonstrated that there were significant differences within this subset between all samplings $(p<0.05)$, with the exception of summer and autumn 2013 ( $p>0.05)$. The species responsible for the differences between these seasons were the 3 dominant species within the assemblage (SIMPER, p < 0.05), B. boops, S. aurita, O. melanura, and also scads in a lesser proportion, because the relative abundances of these species differed among seasons (Table S1 in the Supplement). Winter samplings from both years along with autumn 2012 formed another, more scattered subset (Fig. 3) that was significantly different from the summerssprings-autumn 2013 subset (PERMANOVA, p < 0.001). Similarly, pairwise PERMANOVA revealed significant differences within this second subset $(\mathrm{p}<$ 0.001 ) between all seasons. These differences were mainly caused by changes in the relative abundances of L. ramada and S. salpa, and also by Belone belone, which was particularly abundant during winter 2013 (Table S1).

Component of variation analysis of the assemblage structure revealed that the most important single factors in explaining the overall variation within the wild fish assemblage structure were S $(34.81 \%)$ and 
its random temporal replication D $(20.07 \%)$. Contribution of the factor $\mathrm{Y}$ was only $9.92 \%$, but the interaction of $\mathrm{Y} \times \mathrm{S}$ amounted to $20.99 \%$. The relative importance of factor $\mathrm{F}$ alone $(1.63 \%)$ and its interaction with $\mathrm{S}(\mathrm{S} \times \mathrm{T}$; $6.53 \%$ ) were lower.

\section{Temporal dynamics of dominant wild fish species}

We defined dominant species as those whose seasonal pattern of abundance was outstanding with respect to the whole assemblage: L. ramada and $S$. salpa in winter, $B$. boops and O. melanura in spring and summer, and $S$. aurita and $O$. melanura in autumn.

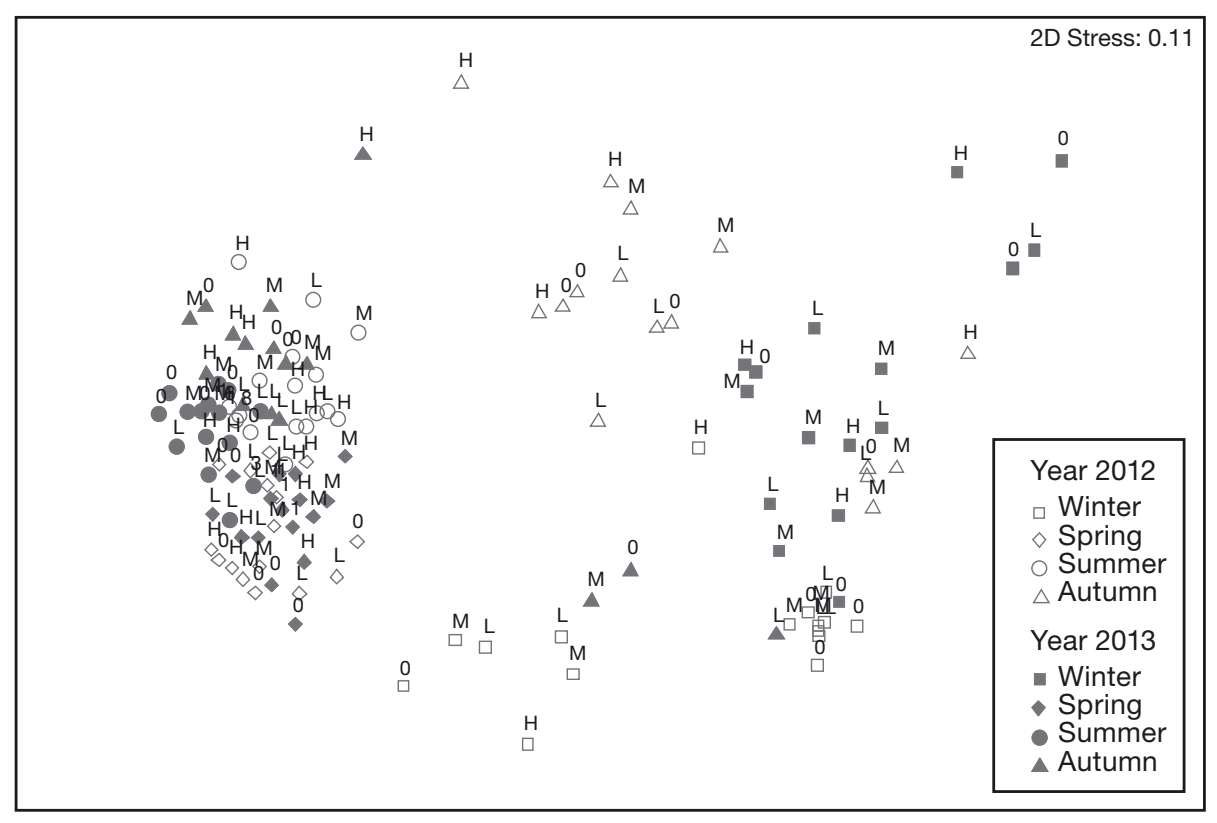

Fig. 3. Non-parametric multidimensional scaling (nMDS) plot for the wild fish assemblage structure at different temporal scales. Letters over symbols indicate different feeding intensities (0: non-feeding; $\mathrm{H}$ : high feeding intensity; $\mathrm{M}$ : medium feeding intensity; L: low feeding intensity)
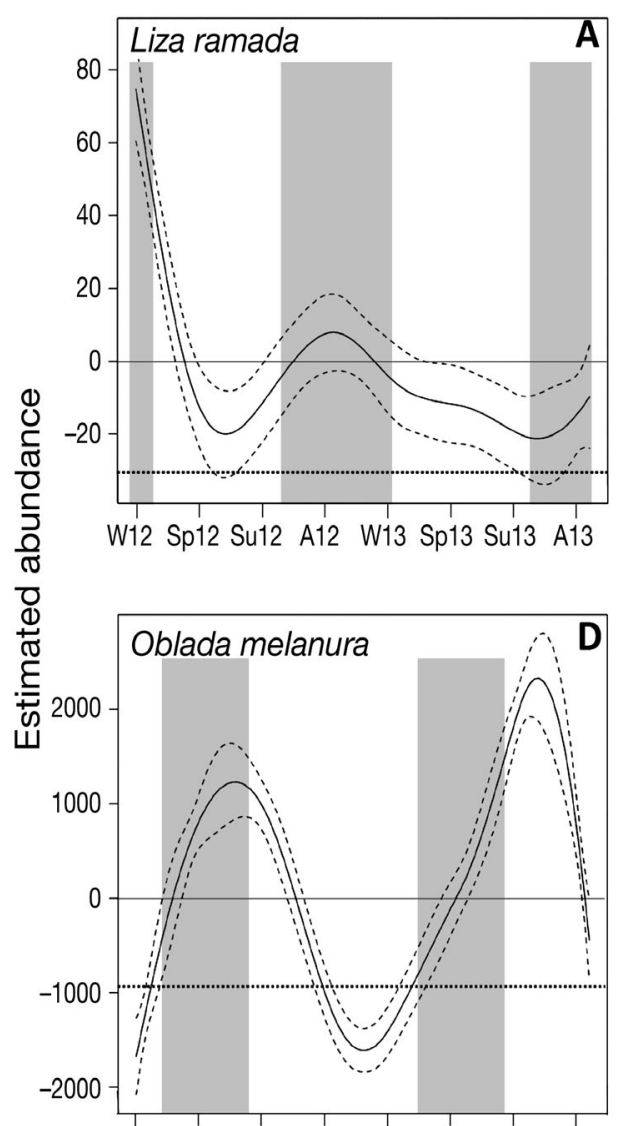

W12 Sp12 Su12 A12 W13 Sp13 Su13 A13
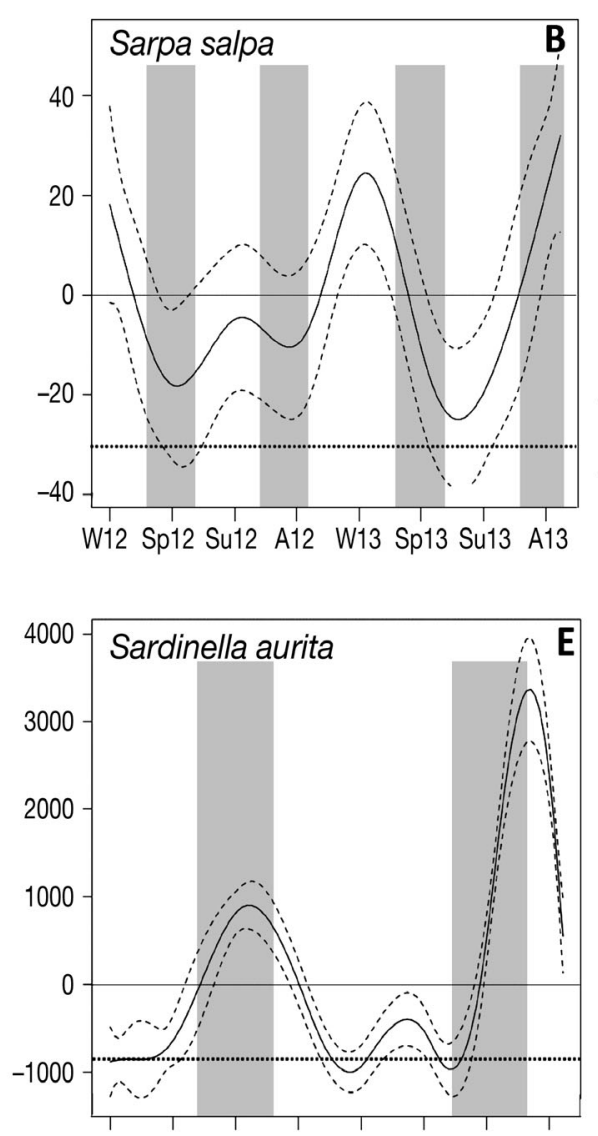

W12 Sp12 Su12 A12 W13 Sp13 Su13 A13

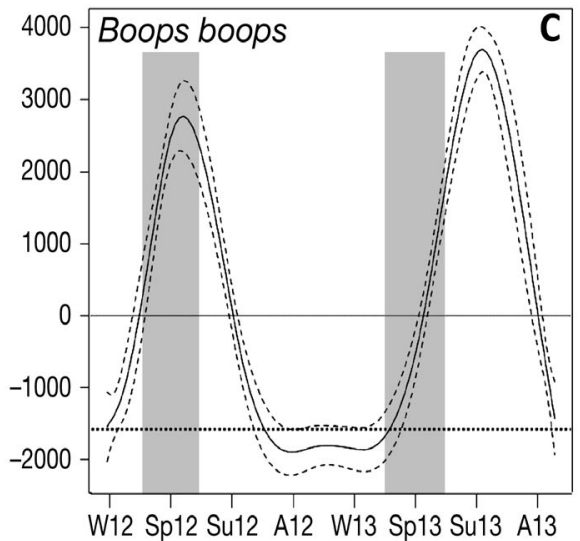

Fig. 4. General additive model estimates of variations in abundance with regards to the average abundance over time for the dominant wild fish species aggregated around the studied fish farm. Dashed line: $95 \%$ confidence interval; dotted horizontal line: estimated average abundance; thin horizontal line: estimated abundance $=0$. Grey bars: reproductive period for $(\mathrm{A})$ Liza ramada (Bartulović et al. 2011), (B) Sarpa sarpa (Criscoli et al. 2006), (C) Boops boops (Alegria-Hernández, 1989), (D) Oblada melanura (Whitehead, 1984) and (E) Sardinella aurita (Sabatés et al. 2006). W: winter; Sp: spring; Su: summer; A: autumn, 12: 2012; 13: 2013 

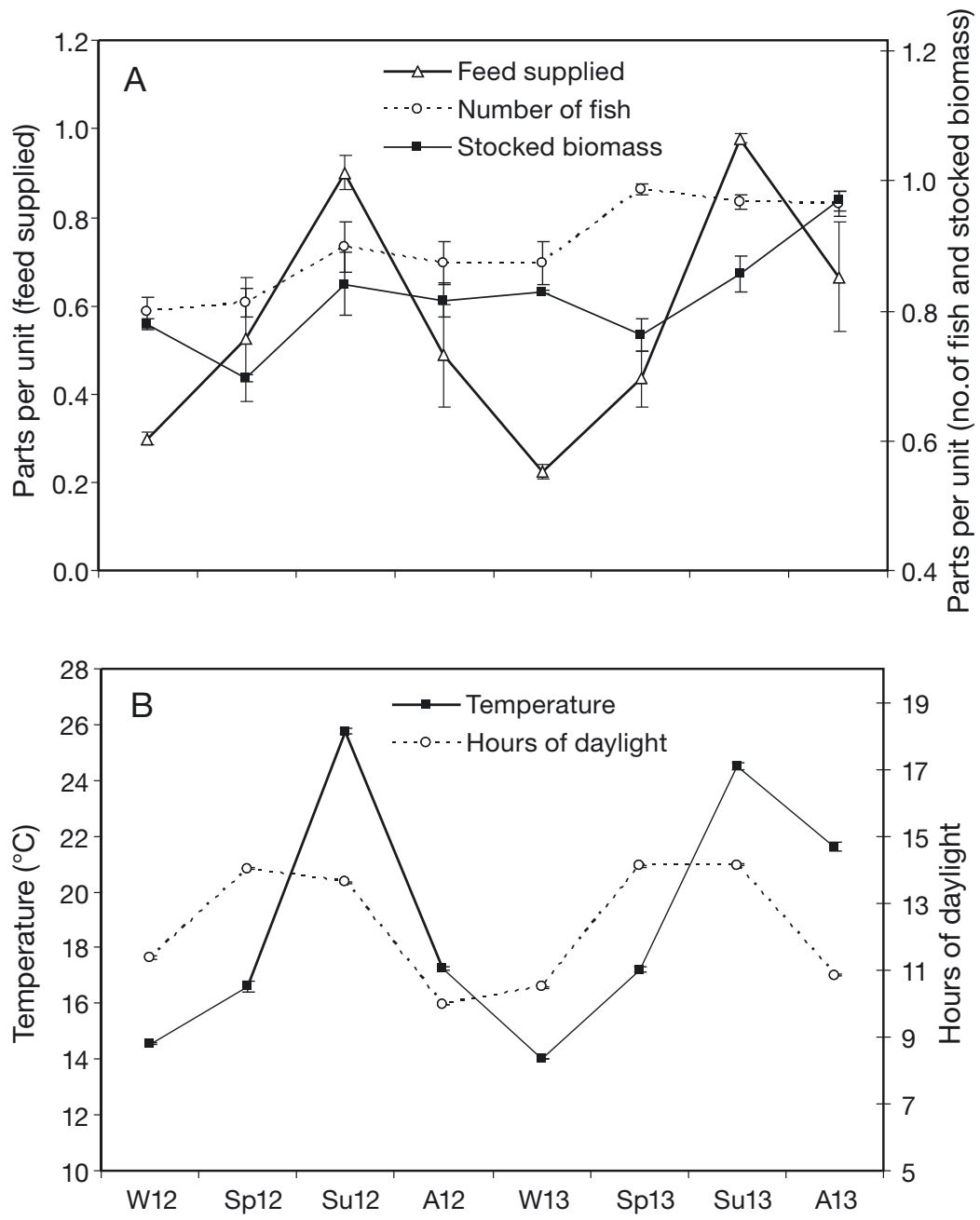

Fig. 5. (A) Average of supplied feed, number of fish and stocked biomass (as parts per unit from the respective reported maximum values) and (B) variation of average temperature and hours of daylight during the study period. W: winter; Sp: spring; Su: summer; A: autumn; 12: 2012; 13: 2013

L. ramada and S. salpa were always aggregated around the farm throughout the whole study period. GAM (Fig. 4A,B) revealed that the presence and abundance of both species did not fit well to any temporal pattern (deviances of 15.6 and $5.48 \%$ for $L$. ramada and $S$. salpa respectively). However, $B$. boops, O. melanura and $S$. aurita showed strong seasonal dynamics. GAM estimates fit very well to the observed values (deviances of 58.8, 42.7 and $38.2 \%$ respectively). For all 3 species, models predicted that periods of low abundance or absence always coincided with non-reproductive phases. After this time, abundance tended to increase until reaching the highest values during the reproductive period in the first year, and just after this in the second year. GAMs also indicated that the maximum abundances of these 3 species did not occur simultaneously (Fig. 4C,E).

\section{Correlation between assemblage structure and environmental and production variables}

Fig. 5A,B shows the variations of environmental and production variables throughout the study period. Total abundance was only significantly correlated with feed supplied $(\mathrm{r}=0.63 ; \mathrm{p}<0.001)$. The wild fish assemblage structure was best explained by the combination of photoperiod and feed supplied (BIOENV, $\rho=0.547 ; \mathrm{p}<0.01)$.

\section{DISCUSSION}

\section{Temporal variability and the influence of environmental and production variables}

The abundance and assemblage structure of wild fish aggregated around the fish farm varied at different temporal scales. The more relevant temporal sources of variation were seasonal changes among years, and (to a lesser extent) aggregation behaviour was also influenced by the feeding activity level of the farm during the seasons of maximum abundance. The production variable that best explained the temporal pattern of abundance was feed supplied, and this variable, combined with hours of daylight, determined the assemblage structure. The outstanding dominant species (Boops boops, Oblada melanura and Sardinella aurita) showed a strong seasonal pattern. These species, although present at the farm most of the year, displayed a distinct maximum abundance related to their reproductive stage, whereas Liza ramada and Sarpa salpa could be considered resident species since their abundances did not undergo major temporal shifts.

Several authors have shown that season is the main temporal source of variation in temperate seas driving wild fish aggregation around fish farms (Dempster et al. 2005, Valle et al. 2007). Our results agree 
with those of Fernandez-Jover et al. (2008), as we also found that seasonal changes may differ among years. These temporal variations can be attributed not only to total fish abundance, but also to assemblage structure. Therefore, our results confirm that this pattern is prevalent in Mediterranean farms, as Fernandez-Jover et al. (2008) suggested. In our work, species composition differed from that of other, even nearby Mediterranean farms (Dempster et al. 2002, Valle et al. 2007, Fernandez-Jover et al. 2008, Bacher et al. 2012), which suggests that assemblage structure is also conditioned by spatial variability. Some authors have shown that wild fish presence around Mediterranean farms is consistent throughout the year (Valle et al. 2007, Dempster et al. 2009, Bacher et al. 2012). However, in our case it was noteworthy that the farm was highly depleted of wild fish during winter. The decrease in day length and feeding intensity (and therefore in waste available to wild fish) would explain this observation. But what is common to most Mediterranean studies is that maximum abundance occurs during the warmest seasons.

Season as a driving factor is determined by key environmental variables such as photoperiod and temperature, which are important for poikilothermic animals like fish. Normally, both variables are closely and positively correlated, since photoperiod changes are responsible for water temperature variations. Photoperiod is the most important and reliable environmental signal for the daily and/or seasonal adjustments of certain biological functions in fish (Prat et al. 1999), such as gonadal maturation and reproduction, whereas temperature acts as 'catalyser' of these functions, overtaking or delaying them (Bromage \& Cumaranatunga 1988, Carrillo et al. 1995). Thus, it would be expected that assemblage structure would be influenced by photoperiod and temperature (Madurell et al. 2004). Nevertheless, in our study, the wild fish community was correlated with photoperiod only, and not with water temperature. This paradoxical situation could be because the increase in abundance of wild fish during spring was not accompanied by a significant rise in temperature in either year. Photoperiod is a constant environmental signal that essentially does not change among years for a given latitude, but water temperatures may experience variations among years in the same season, as occurred in our study. Hence, the differences observed between seasons within years in our study must be also have been determined by factors other than photoperiod.

Dempster et al. (2005) suggested that the input of organic matter from a fish farm may influence the wild fish that aggregated around it. Organic matter input is considered to be the main attractant for wild fish around fish farms (Tuya et al. 2006, FernandezJover et al. 2008, Uglem et al. 2009, Bacher et al. 2012, 2015), although its variation as a function of temporal variability has not been evaluated. Obviously, organic input is a direct function of the supplied feed, and consequently of the stocked biomass. In the Mediterranean, the highest fish feed intake and growth occur during the warmer months, normally in summer. However, maximum feed intake and growth do not always coincide with the time of maximum stocked biomass and supplied feed, which may depend on husbandry as well as on season. In our study, seasonal changes in abundance and assemblage structure occurred between years, and only supplied feed resulted in correlation with both variables. Therefore, the highest abundance and the corresponding assemblage structure were conditioned by the amount of supplied feed, which does not always coincide with the warmest season (Piedecausa et al. 2010). Fernandez-Jover et al. (2008) did not find any clear temporal relationship between the maximum wild fish biomass and the availability of feed (as measured by the stomach pellet content of wild fish) around Mediterranean seabream Sparus aurata and seabass Dicentrarchus labrax farms. Similarly, no correlation was found between wild fish abundance and stocked biomass (Dempster et al. 2009) or the number of cages as a proxy of stocked biomass (Goodbrand et al. 2013) in Atlantic salmon Salmo salar farms.

Under farming conditions, captive fish exhibit an anticipatory behaviour in response to external conditioning factors such as feeding schedule, human presence, boat noise, etc. (Mistlberger 1994, Montoya et al. 2010). Two previous studies following different approaches demonstrated that feeding activity within a fish farm may determine the behaviour of aggregated wild fish (Sudirman et al. 2009, Bacher et al. 2015), but neither of them combined feeding intensity with any other temporal sources of variation. Both studies reported that maximum aggregation occurred during feeding time. Similarly, Uglem et al. (2009) observed that the movement pattern of wild saithe Pollachius virens around salmon farms was also strongly related with feeding times. Feeding intensity may change throughout the day and over the seasons depending on environmental variables and the husbandry arrangement of each farm. In our case, samplings were conducted 4 times during the day when farming activities were different, including a non-feeding period early in the morning (8:00 h), a 
full feeding period $(11: 00 \mathrm{~h})$, a medium feeding period $(13: 00 \mathrm{~h})$ and a low feeding period $(16: 00 \mathrm{~h})$. During the warmest seasons (summer and autumn; and also in spring although there were no significant differences), wild fish abundance was high just before the feeding activity began. When the farm was fully operational, wild fish abundance remained high or even increased. In the periods of lower farming activity that followed, the abundance decreased considerably. These results agree with the previously mentioned works, but also demonstrate that wild fish also exhibit the same anticipatory feeding behaviours as captive fish. For the remaining seasons when the organic input was low, wild fish assemblage behaviour throughout the day was somewhat unpredictable. However, this kind of change in abundance linked to the warmest season and feeding intensity times only corresponded to a significant variation in the assemblage structure during autumn of the second year (a particularly warm autumn). In this case, the leading but non-resident fish species (S. aurita, $O$. melanura and $B$. boops) dominated during the preand full-feeding periods, but were found in much lower abundance in the subsequent periods. On the contrary, the abundance of the resident species ( $L$. ramada and $S$. salpa) was low early in the morning and increased as the abundance of the dominant species decreased. Hence, we have illustrated here that maximum aggregation and structuring of wild fish around fish farms is not only driven by seasonality and annual randomness, but also by the dynamics of the culture, at least for the dominant planktivorous species. This close relationship between fish farms and wild fish could affect the distribution of some species, as has been suggested for saithe $P$. virens in the North Sea (Otterå \& Skilbrei 2014). Similarly, the migration behaviour of some large predatory fish such as Atlantic bluefin tuna Thunnus thynnus thynnus, a persistent fish species at our studied farm, may also be altered as a consequence of the attraction to some fish farms in the Mediterranean (ArechavalaLopez et al. 2015).

\section{Temporal dynamics of dominant species}

In general, wild fish assemblages that are aggregated around fish farms are strongly dominated by only a few species (Dempster et al. 2005, 2009, Valle et al. 2007, Fernandez-Jover et al. 2008, Bacher et al. 2012) which may reduce the positive ecological effects of the artificial habitat created around the fish farms (Riera et al. 2014) by reducing biodiversity.
Paying special attention to dominant wild fish species is important since most structural changes can be explained by only these species. Different species exhibit species-specific aggregation patterns, depending on their ecology (Bacher et al. 2012). Most studies only associate the presence and/or abundance of some fish species with a particular temporal scale (Dempster et al. 2002, Boyra et al. 2004, Valle et al. 2007, Fernandez-Jover et al. 2008, Uglem et al. 2009, Sudirman et al. 2009, Segvić Bubić et al. 2011, Bacher et al. 2012). Modelling the temporal dynamic of dominant species allows us to predict the distribution of these species around fish farms (ArechavalaLopez et al. 2010). In our case, GAMs estimated that the maximum abundance of the most dominant species (B. boops, O. melanura and S. aurita) did not occur at the same time, despite the fact that all 3 species coexist around the farm during warmest seasons and virtually disappear during the colder ones. Also, GAMs showed that the abundance of all 3 species increased profusely around the farm coinciding with their maturation and spawning phases. This kind of reproductive migration towards and away from the farm was postulated by Fernandez-Jover et al. (2008), and can be explained by the optimal foraging paradigm (Werner et al. 1983). In our study, the warmer autumn of the second year could be the cause of the slightly delayed maximum abundance of the 3 species during that year. As discussed above, the farm influence could modify the reproductive behaviour of these species.

GAMs provided poorly fit estimates of average abundance over time for both L. ramada and S. salpa. These resident species, despite their low relative abundance, dominated the assemblage during those seasons in which the 3 abovementioned species were away from the farm, when variations in their abundance over time around the farm appeared to be somewhat random. B. boops, O. melanura and $S$. aurita are pelagic species that carry out seasonal migratory reproductive movements to the farm, and then leave the area once their reproductive period is over. In contrast, L. ramada and S. salpa are nektonic species whose natural habitats (seagrass meadows, rocky reefs) are very close to the farm, which favors their presence in the vicinity of the farm throughout the year.

\section{Implications for environmental management}

Wild fish have the ability to minimize the environmental impacts caused by fish farming because of 
their potential capacity for reutilization and dispersion of farm wastes (Katz et al. 2002, Vita et al. 2004, Dempster et al. 2005, 2009, Fernandez-Jover et al. 2008). It is generally accepted that in the Mediterranean, maximum organic release from fish farms occurs during the warmest seasons, while late-autumn and winter serve as somewhat of a fallowing period because of the lower fish growth and lower amount of feed supplied. Nevertheless, despite the decrease in organic input during the cold periods, the corresponding low abundance of wild fish (as occurred in our study case) could be detrimental to the local environment, since the waste recycling function carried out by wild fish practically vanishes during that period. Furthermore, the remaining wild fish also reduce their feed intake during cold periods (Burel et al. 1996, Buentello et al. 2000). Some attempts have made to model aquaculture and environment energy fluxes (Díaz López et al. 2008, Ren et al. 2012, BayleSempere et al. 2013). However, the abundance and temporal dynamics of the dominant planktivorous wild fish and the temporal pattern of farm waste output (Piedecausa et al. 2010) should also be considered in order to estimate the contribution of wild fish to the mitigation of adverse environmental effects of fish farming.

Acknowledgements. This research was funded by the Spanish Institute of Agro-Forestry Research (INIA; Ministry of Economy and Competitiveness; project RTA2011-00088-00$00)$. The study was also partially sponsored by the studentgrant Sub-Programme of Researcher Formation of the Spanish Institute of Agro-Forestry Research (FPI-INIA). The authors thank all the operators of the collaborating fish farm company, as well as Sergio Eguía Martínez, María Martí Gálvez, Fulgencio Tárraga López and Juan Manuel Ruiz Fernández for their assistance during field samplings.

\section{LITERATURE CITED}

Alegria-Hernández V (1989) Study on the age and growth of Bogue (Boops boops (L.)) from Central Adriatic Sea. Cybium 13:281-288

Anderson MJ (2001) A new method for non-parametric multivariate analysis of variance. Austral Ecol 26:32-46

Anderson MJ, Gorley RN, Clarke KR (2008) PERMANOVA+ for PRIMER: guide to software and statistical methods. PRIMER-E, Plymouth

> Arechavala-Lopez P, Uglem I, Sanchez-Jerez P, FernandezJover D, Bayle-Sempere J, Nilsen R (2010) Movements of grey mullet Liza aurata and Chelon labrosus associated with coastal fish farms in the western Mediterranean Sea. Aquacult Environ Interact 1:127-136

Arechavala-Lopez P, Borg JA, Šegvić-Bubić T, Tomassetti P, Özgül A, Sanchez-Jerez P (2015) Aggregations of wild Atlantic bluefin tuna (Thunnus thynnus L.) at Mediterranean offshore fish farm sites: environmental and man- agement considerations. Fish Res 164:178-184

Bacher K, Gordoa A, Sague O (2012) Spatial and temporal extension of wild fish aggregations at Sparus aurata and Thunnus thynnus farms in the north-western Mediterranean. Aquacult Environ Interact 2:239-252

Bacher K, Gordoa A, Sagué O (2015) Feeding activity strongly affects the variability of wild fish aggregations within fish farms: a sea bream farm as a case study. Aquacult Res 46:552-564

Bartulović V, Dulčić J, Matić-Skoko S, Glamuzina B (2011) Reproductive cycles of Mugil cephalus, Liza ramada and Liza aurata (Teleostei: Mugilidae). J Fish Biol 78: 2067-2073

Bayle-Sempere JT, Arreguín-Sánchez F, Sanchez-Jerez P, Salcido-Guevara LA, Fernandez-Jover D, Zetina-Rejón MJ (2013) Trophic structure and energy fluxes around a Mediterranean fish farm. Ecol Modell 248:135-147

Bjordal ^̊, Skar AB (1992) Tagging of saithe (Pollachius virens L.) at a Norwegian fish farm: preliminary results on migration. ICES CM 1992/G:35, ICES, Bergen

Boyra A, Sanchez-Jerez P, Tuya F, Espino F, Haroun R (2004) Attraction of wild coastal fishes to an Atlantic subtropical cage fish farms, Gran Canaria, Canary Islands. Environ Biol Fishes 70:393-401

Bromage N, Cumaranatunga R (1988) Egg production in the rainbow trout. In: Muir J, Roberts R (eds) Recent advances in aquaculture. Springer, Netherlands, p 63-138

$>$ Buentello JA, Gatlin DM III, Neill WH (2000) Effects of water temperature and dissolved oxygen on daily feed consumption, feed utilization and growth of channel catfish (Ictalurus punctatus). Aquaculture 182:339-352

> Burel C, Person-Le Ruyet J, Gaumet F, Le Roux A, Sévère A, Boeuf G (1996) Effects of temperature on growth and metabolism in juvenile turbot. J Fish Biol 49:678-692

Carrillo M, Zanuy S, Prat F, Cerdá J, Ramos J, Mañanos E, Bromage N (1995) Sea bass. In: Bromage NR, Roberts RJ (eds) Broodstock management and egg and larval quality. Blackwell, Oxford, p 138-168

Carss DN (1990) Concentrations of wild and escaped fishes immediately adjacent to fish farm cages. Aquaculture 90: $29-40$

> Clarke KR (1993) Non-parametric multivariate analyses of changes in community structure. Aust J Ecol 18:117-143

Clarke K, Ainsworth M (1993) A method of linking multivariate community structure to environmental variables. Mar Ecol Prog Ser 92:205-219

Clarke KR, Gorley RN (2006) PRIMER v6: User manual/ tutorial. PRIMER-E, Plymouth

Clarke KR, Warwick RM (1994) Change in marine communities: an approach to statistical analysis and interpretation. PRIMER-E, Plymouth

Criscoli A, Colloca F, Carpentieri P, Belluscio A, Ardizzone G (2006) Observations on the reproductive cycle, age and growth of the salema, Sarpa salpa (Osteichthyes: Sparidae) along the western central coast of Italy. Sci Mar 70:131-138

> Dempster T, Sanchez-Jerez P, Bayle-Sempere JT, GiménezCasalduero F, Valle C (2002) Attraction of wild fish to sea-cage fish farms in the south-western Mediterranean Sea: spatial and short-term temporal variability. Mar Ecol Prog Ser 242:237-252

Dempster T, Sanchez-Jerez P, Sempere J, Kingsford M (2004) Extensive aggregations of wild fish at coastal seacage fish farms. Hydrobiologia 525:245-248

> Dempster T, Fernandez-Jover D, Sanchez-Jerez P, Tuya F, 
Bayle-Sempere J, Boyra A, Haroun RJ (2005) Vertical variability of wild fish assemblages around sea-cage fish farms: implications for management. Mar Ecol Prog Ser 304:15-29

> Dempster T, Uglem I, Sanchez-Jerez P, Fernandez-Jover D, Bayle-Sempere J, Nilsen R, Bjørn P (2009) Coastal salmon farms attract large and persistent aggregations of wild fish: an ecosystem effect. Mar Ecol Prog Ser 385: $1-14$

> Dempster T, Sanchez-Jerez P, Uglem I, Bjørn PA (2010) Species-specific patterns of aggregation of wild fish around fish farms. Estuar Coast Shelf Sci 86:271-275

> Deudero S (2001) Interspecific trophic relationships among pelagic fish species underneath FADs. J Fish Biol 58: 53-67

> Díaz López B, Bunke M, Bernal Shirai JA (2008) Marine aquaculture off Sardinia Island (Italy): ecosystem effects evaluated through a trophic mass-balance model. Ecol Modell 212:292-303

> Fernandez-Jover D, Sanchez-Jerez P, Bayle-Sempere JT, Valle C, Dempster T (2008) Seasonal patterns and diets of wild fish assemblages associated with Mediterranean coastal fish farms. ICES J Mar Sci 65:1153-1160

Fernandez-Jover D, Sanchez-Jerez P, Bayle-Sempere JT, Arechavala-Lopez P, Martinez-Rubio L, Jimenez JAL, Lopez FJM (2009) Coastal fish farms are settlement sites for juvenile fish. Mar Environ Res 68:89-96

> Fletcher D, Underwood A (2002) How to cope with negative estimates of components of variance in ecological field studies. J Exp Mar Biol Ecol 273:89-95

> Goodbrand L, Abrahams MV, Rose GA (2013) Sea cage aquaculture affects distribution of wild fish at large spatial scales. Can J Fish Aquat Sci 70:1289-1295

Harmelin-Vivien ML, Francour P (1992) Trawling or visual censuses? Methodological bias in the assessment of fish populations in seagrass beds. Mar Ecol 13:41-51

Harmelin-Vivien M, Harmelin J (1975) Présentation d'une méthode d'évaluation 'in situ' de la fauna ichtyologique. Travaux Sci Parc Natl Port-Cros 1:47-52

Harmelin-Vivien M, Harmelin J, Chauvet C, Duval C and others (1985) Evaluation visuelle des peuplements et populations de poissons: methodes et probleme. Rev Ecol Terre Vie 40:467-539

Katz T, Herut B, Genin A, Angel DL (2002) Gray mullets ameliorate organically enriched sediments below a fish farm in the oligotrophic Gulf of Aqaba (Red Sea). Mar Ecol Prog Ser 234:205-214

> Madurell T, Cartes JE, Labropoulou M (2004) Changes in the structure of fish assemblages in a bathyal site of the Ionian Sea (eastern Mediterranean). Fish Res 66:245-260

Mistlberger RE (1994) Circadian food-anticipatory activity: formal models and physiological mechanisms. Neurosci Biobehav Rev 18:171-195

Montoya A, López-Olmeda JF, Yúfera M, Sánchez-Muros MJ, Sánchez-Vázquez FJ (2010) Feeding time synchronises daily rhythms of behaviour and digestive physiology in gilthead seabream (Sparus aurata). Aquaculture 306:315-321

Norton J (1999) Apparent habitat extensions of dolphinfish (Coryphaena hippurus) in response to climate transients in the California Current. Sci Mar 63:239-260

Otterå H, Skilbrei OT (2014) Possible influence of salmon farming on long-term resident behaviour of wild saithe (Pollachius virens L.). ICES J Mar Sci 9:2484-2493
Özgül A, Angel D (2013) Wild fish aggregations around fish farms in the Gulf of Aqaba, Red Sea: implications for fisheries management and conservation. Aquacult Environ Interact 4:135-145

Piedecausa MA, Aguado-Giménez F, Cerezo-Valverde J, Hernández-Llorente MD, García-García B (2010) Simulating the temporal pattern of waste production in farmed gilthead seabream (Sparus aurata), European seabass (Dicentrarchus labrax) and Atlantic bluefin tuna (Thunnus thynnus). Ecol Modell 221:634-640

Prat F, Zanuy S, Bromage N, Carrillo M (1999) Effects of constant short and long photoperiod regimes on the spawning performance and sex steroid levels of female and male sea bass. J Fish Biol 54:125-137

> Ren JS, Stenton-Dozey J, Plew DR, Fang J, Gall M (2012) An ecosystem model for optimising production in integrated multitrophic aquaculture systems. Ecol Modell 246:34-46

> Riera R, Sanchez-Jerez P, Rodriguez M, Monterroso O (2014) Artificial marine habitats favour a single fish species on a long-term scale: the dominance of Boops boops around off-shore fish cages. Sci Mar 78:505-510

Sabatés A, Martín P, Lloret J, Raya V (2006) Sea warming and fish distribution: the case of the small pelagic fish, Sardinella aurita, in the western Mediterranean. Glob Change Biol 12:2209-2219

Schneider DC (1994) Quantitative ecology: spatial and temporal scaling. Academic Press, San Diego, CA

Segvić Bubić T, Grubišić L, Tičina V, Katavić I (2011) Temporal and spatial variability of pelagic wild fish assemblages around Atlantic bluefin tuna Thunnus thynnus farms in the eastern Adriatic Sea. J Fish Biol 78:78-97

Sudirman, Halide H, Jompa J, Zulfikar, Iswahyudin, McKinnon AD (2009) Wild fish associated with tropical sea cage aquaculture in South Sulawesi, Indonesia. Aquaculture 286:233-239

Tuya F, Sanchez-Jerez P, Dempster T, Boyra A, Haroun RJ (2006) Changes in demersal wild fish aggregations beneath a sea-cage fish farm after the cessation of farming. J Fish Biol 69:682-697

Uglem I, Dempster T, Bjørn PA, Sanchez-Jerez P, Økland F (2009) High connectivity of salmon farms revealed by aggregation, residence and repeated movements of wild fish among farms. Mar Ecol Prog Ser 384:251-260

Uglem I, Karlsen Ø, Sanchez-Jerez P, Sæther BS (2014) Impacts of wild fishes attracted to open-cage salmonid farms in Norway. Aquacult Environ Interact 6:91-103

- Valle C, Bayle-Sempere JT, Dempster T, Sanchez-Jerez P, Giménez-Casalduero F (2007) Temporal variability of wild fish assemblages associated with a sea-cage fish farm in the south-western Mediterranean Sea. Estuar Coast Shelf Sci 72:299-307

Vita R, Marín A, Madrid J, Jiménez-Brinquis B, Cesar A, Marín-Guirao L (2004) Effects of wild fishes on waste exportation from a Mediterranean fish farm. Mar Ecol Prog Ser 277:253-261

> Werner EE, Mittelbach GG, Hall DJ, Gilliam JF (1983) Experimental tests of optimal habitat use in fish: the role of relative habitat profitability. Ecology 64:1525-1539

Whitehead PJP (1984) Fishes of the north-eastern Atlantic and the Mediterranean. UNESCO, Paris

> Wood SN (2011) Fast stable restricted maximum likelihood and marginal likelihood estimation of semiparametric generalized linear models. J R Stat Soc Series B Stat Methodol 73:3-36

Submitted: March 23, 2015; Accepted: August 16, 2015

Proofs received from author(s): October 2, 2015 